\title{
Inventories, financial structure and market structure
}

\author{
Josep A. Tribó
}

Departamento de Economía de la Empresa, Universidad Carlos III, C/ Madrid 126, 28903 Getafe (Madrid), Spain

\begin{abstract}
In this paper, we study the effect of different financial contracts on the firm's inventory policy. Doing so will allow to define the best financial instruments to diminish the stock variability of a profit-maximizing firm in a given economic environment (expansion or recession), and for a given market structure. We show that in periods of recession (expansion), reducing (increasing) the amount of short-term debt is an optimal strategy independently of the market structure.
\end{abstract}

Keywords: Inventories; Financial structure; Market structure

\section{Introduction}

This paper studies the impact of product differentiation and financial structure on firms' inventory policy. This type of analysis is supposed to deliver a global perspective on the interaction between input and output markets, and the dynamics of firms' inventories. We believe that this is a relevant question insofar the variability of firms' stocks is recognized to be one of the driving forces of business cycle fluctuations.

In order to give a broad idea of this phenomenon, Blinder and Maccini [1] find that up to $87 \%$ of GDP variance during short-term (ST henceforth) recessions is linked with drastic inventory reductions. ${ }^{1}$ Other sources ${ }^{2}$ find that as much as $11 \%$ of Chinese GDP is stored in stocks. From these pieces

\footnotetext{
E-mail address: joatribo@emp.uc3m.es (J.A. Tribó).

${ }^{1}$ See also The Economist, 1999, April 24th, "The Economics of Inventories".

2 "China's Inventory Problem" in The Wall Street Journal, 1997, April 14th.
}

of evidence we can understand the rationale for a Central Authority to give incentives to profitmaximizing firms for smoothing their steep inventory disinvestment (investment) in recessions (expansions). Hendel [2] links this issue with firms liquidity needs in the ST. Firms tend to increase their cash reserves through an aggressive stock disinvestment in order to satisfy ST financial obligations. In this perspective, it is an issue of interest to study the firms' interaction between inventory policy and their financial structure. Other studies such as Carpenter et al. [3], Kashyap et al. [4] and Olney [5] find a stronger impact of cyclical fluctuations on small firms' inventory variability than on that of bigger firms. These authors link this result to the fact that smaller firms can only obtain external funds through credits with ST maturities. On the other hand, larger firms can also obtain long-term (LT henceforth) financing (LT debt or equity).

Here we propose a model in which firms are hit by both economy-wide supply-side and economy-wide demand-side shocks. Focusing on 
economy-wide shocks allows us to avoid aggregation issues among different markets subject to idiosyncratic shocks. Furthermore, economywide shocks are those which trigger expansions or recessions.

In our setup, firms compete in a monopolistic competitive market, designing their inventory policy as a profit maximizing function of their financial structure, the shocks, and the market structure. We consider different financial contracts that link firms with their fund providers. This allows us to study the effect of different financial instruments (debt or equity) with different lenders (banks or market) on a profit-maximizing firm's stock policy under alternative market structures. Such an analysis has normative implications for a Central Authority that would affect firms' financial structure as a way to smooth inventory fluctuations and ultimately, cyclical fluctuations.

Four main results are obtained in our model. First, the impact of product market differentiation on inventory investment is such that, in expansions, the inventory variance increases as markets become more fragmented, and vice versa in recessions. Second, regarding the role of firms financial structure, we prove that market debt-financed firms store a lower inventory level than bank debt-financed firms, which in turn accumulate less than equityfinanced firms. Third, the higher (lower) the amount of ST debt in expansions (recessions), the lower stock fluctuations in expansions (recessions) for a profit-maximizing firm. This in turn implies that firms using variable-rate credit define a smoother inventory policy than firms using fixed-rate credits. Finally, we describe a possible mechanism that would provide profit-maximizing firms with cheap financing and at the same time smooth their inventory accumulation policy.

The paper is organized as follows. Section 2 sketches our basic model. In Section 3 we solve the model and present our main findings. Section 4 concludes.

\section{The basic model}

We consider a one-period model populated with two agents. (i) A representative firm that follows a profit-maximizing policy and accumulates inventories as residuals. (ii) Lenders, who compete in order to provide the firm with the required external funds, $E$, at the beginning of the period. These funds can be obtained making use of debt or equity. We assume feasibility, in the sense that the firm can raise all the external funds it needs. Lenders therefore play a passive role in our model, that simply consists in recovering their capital. Let $B$ denote the firm's debt payment obligations at the end of the period. This value is composed by some inherited past LT debt, to be returned at the end of the period considered, $B_{p}$, as well as the current one-period debt, $B_{s}{ }^{3}$

The representative firm is producing in a monopolistic competitive market, composed by a large number of firms, facing each a stochastic inverse demand function $\tilde{p}_{i}=\tilde{a}-b q_{i}-(1-b) \hat{Q}$, where $i$ indexes the generic firm, and $\hat{Q}$ refers to the industry average output. The parameter $\tilde{a}$ is an economy-wide stochastic variable, independently and identically distributed with a uniform distribution over an interval $[a, \bar{a}]$. The parameter $b$ rises with the degree of product differentiation. As $b$ tends to 1 , the product market evolves from competitive to monopolistic. Firms face a stochastic marginal production cost, $\tilde{c}$, subject to an economy-wide shock $\tau$ that follows an independent distribution function uncorrelated with demand shocks $\tilde{a}$. We assume a constant marginal storage $\operatorname{cost} A$, and we consider the possibility of inheriting backlogs from the past. That is, in every period, firm's stocks may also be negative. We make a first-order analysis, and, similarly as for production costs, we consider a profit function where the marginal benefit to store stocks is constant $(\lambda) .^{4}$ This $\lambda$ value can be interpreted as an entrepreneur stock shadow price. We are going to relate this $\lambda$ with the proportion of firm's long-length financial

\footnotetext{
${ }^{3}$ The quantities $B_{p}$ and $B_{s}$ result in imposing a lender zeroprofit condition on the corresponding $L T$ funds raised in the past, as well as all $S T$ funds raised in the present, respectively.

${ }^{4}$ Although we only analyze one period, there are others, otherwise firms would not store stocks. We introduce these other periods in firm profits function through firm valuation of end-of-the period inventories, $n_{i, 1}$. By simplicity, I have assumed a linear function $\left(\lambda n_{i, 1}\right)$.
} 
obligations as well as the type of lender. Firms are capacity bounded to produce a $\bar{y}$ amount, with $\bar{y} \geqslant\left(\bar{a}-\lambda_{0}\right) /(1+b)-n_{0}{ }^{5}$ where $n_{0}$ is the firm's initial stock level, and $\lambda_{0}$ is the initial value of $\lambda$.

There are two types of debt lenders: banks and the market. Bank debt is more easy to renegotiate than market debt is. Thus, once a firm cannot satisfy its cash payments, banks, unlike the market, permit payment with a transference of inventory rights to be transformed in cash in the near future. This fact has two consequences in entrepreneur stock shadow price $\lambda$. First, in a bank-financed firm, $\lambda$ is higher than in a market-financed firm. Second, the inventory shadow price for a bank, $\lambda^{\text {Bank }}$, is higher than for the market, $\lambda^{\text {Market }}$. In particular, for simplicity we fix $\lambda^{\text {Market }}=0$, as we have assumed that market debt cannot be paid selling inventory rights, and $\lambda^{\text {Bank }}=\lambda$.

It is well documented in the literature [6] that the higher the proportion of a firms' long-length financial instrument, the higher the firms' investment, and, in particular, inventory investment. We model this fact by considering a high-stock "shadow price" $\lambda$ in those scenarios in which a firm's financing is based on LT financial instruments. Inventories in the medium term could easily be transformed in cash in order to attain the required LT debt payments. In addition, inventories can be used as collateral to extend the length (roll over), when necessary, of today's LT credits. Both facts positively correlate the size of the LT debt (both historical and from the current period) with $\lambda$. To summarize, $\lambda$ is higher for bank debt-financed firms, and especially if it is long-term debt.

\section{Timing of events}

$-F-0-1$

At time $F$, the financing stage, the entrepreneur borrows an amount $E$ of funds in a competitive credit market, using different instruments (bank debt, market debt or equity). In the case of debt financing, the financial contract designed establishes a collateral that includes firm's stocks, and

\footnotetext{
${ }^{5}$ Condition $n_{0}+\bar{y}-\left(\bar{a}-\lambda_{0}\right) /(1+b) \geqslant 0$ ensures that production $\bar{y}$ is high enough to eliminate all possible backlogs, even if demand is maximum $\left(a_{i, 1}=\bar{a}\right)$.
}

a payment obligation $B$. As above, we assume feasibility, i.e. firms obtains all the funds they need.

At time 0 there is a supply shock, $\tau_{0}$, that determines the marginal production costs, $c_{0}$, for the period considered. The entrepreneur, once obtained the funds $E$, chooses production $y_{i, 1}$, taking into account $c_{0}$, the firm's initial stock level, $n_{0}$, the initial value of $\lambda\left(\lambda_{0}\right)$, and the expected period-one demand shock, $a_{1}$.

At the end of the period (time 1), the demand shock $a_{1}$ is realized. The entrepreneur decides how much to sell $\left(q_{i, 1}\right)$ and satisfies his or her ST debt payments $B$. Otherwise, lenders take the control of the firm and liquidate the collateral, which included the firm's stocks.

\section{Solving the model}

The firm inherits a particular financial structure from the past, based on equity and debt. We distinguish two financing scenarios: bank debt and market debt. In the first (second) situation the firm raises funds in the period studied, by means of bank (market) debt, that can be LT or ST, as well as issuing equity. We also contemplate a pure equity financing framework, with no debt claims $(B=0)$.

Our objective is to study the firm's inventory fluctuations, measured substracting the average final inventory level, $\hat{n}_{1}$ from the initial level $n_{0}$, under different financing scenarios and market structures. Although this might not be a fully comprehensive definition of inventory fluctuations, it is the only one that is feasible in a one-period model.

\subsection{Bank debt financing}

Under this scenario, the firm obtains funds in the current period by means of bank debt (ST or LT), and additionally, if so, with equity (selling its own shares in the financial market, or making a share issue). This implicitly defines the firm's stock shadow price for the period, $\lambda_{0}$, which is positively correlated with debt length. We assume that whenever the firm's "liquid" profits (excluding $\lambda_{0} n_{1}$ from the profit function of Eq. (1)) are lower than ST 
claims, $B$, the bank, accepts compensation acquiring senior rights over the remaining stocks without triggering a liquidation of the collateral. This fact makes liquidity consideration for bank-financed firms less relevant than for market-financed firms, who cannot satisfy their payments by transferring inventory rights.

To solve the model, we first compute the firm's sales at the end of the period $\left(q_{i, 1}\right)$, once the demand shock $a_{1}$ is known. Two cases can be distinguished. When $a_{1}$ is low, the entrepreneur cannot fulfill bank payments, even by transferring inventory rights, thus losing the firm's control, with a consequent liquidation of all the existences $\left(q_{i, 1}=n_{i, 0}+y_{i, 1}\right)$. When $a_{1}$ is high, the entrepreneur maximizes the profit function at $t=1\left(V_{i, 1}\right)$ :

$\underset{\left\{q_{i, 1}\right\}}{\operatorname{Max}} V_{i, 1} \equiv R_{i, 1}-c_{0} y_{i, 1}-A n_{i, 0}+\lambda_{0} n_{i, 1}-B$,

where $R_{i, 1} \equiv\left[a_{1}-b q_{i, 1}-(1-b) \hat{Q}\right]_{q_{i, 1}}$ denotes first-period revenues, and $n_{i, 1}=n_{i, 0}+y_{i, 1}-q_{i, 1}$ denotes the stock level at the end of the period.

This gives the solution

$q_{i, 1}= \begin{cases}\frac{a_{1}-\lambda_{0}}{1+b} & \text { if } X_{1} \leqslant a_{1}, \\ n_{i, 0}+y_{i, 1} & \text { if } a_{1}<X_{1},\end{cases}$

where $X_{1}$ is a threshold value for $a_{1}$ such that $V_{i, 1}\left[a_{1}=X_{1}\right]=0$.

$$
\begin{aligned}
& \left(X_{1}-\lambda_{0}\right)^{2}-\left(1-b^{2}\right)\left(X_{1}-\lambda_{0}\right) \hat{Q} \\
& \quad+(1+b)^{2}\left(\varepsilon_{0} y_{i}-\left(A-\lambda_{0}\right) n_{i, 0}-B\right)=0 .
\end{aligned}
$$

To derive this expression, we have to substitute firms sales policy (2) in Eq. (1) and impose $V_{i, 1}=0$. This expression is simplified once we assume a symmetric solution $q_{i, 1}=\hat{Q}$. This is the case because we are dealing with the market representative firm.

Note that in the case of no liquidation $\left(a_{1} \geqslant X_{1}\right)$, sales decrease with $\lambda_{0}$. Stocks become more valuable for the entrepreneur and he or she is more willing to accumulate inventories by reducing sales. The standard result over the positive correlation between the degree of market competitiveness ( $b$ low) and sales is also found. To compute the firm's production, $y_{i, 1}$, we maximize firm expected profit function at time $t=0,\left(V_{i, 0}\right)^{:^{6}}$

$$
\begin{array}{r}
\operatorname{Max}_{\left\{y_{i, 1}\right\}} V_{i, 0} \equiv \int_{X_{1}}^{\bar{a}}\left\{R_{i, 1}-c_{0} y_{i, 1}-A n_{i, 0}\right. \\
\left.+\lambda_{0} n_{i, 1}-B\right\} \frac{\mathrm{d} a_{1}}{\Delta a}
\end{array}
$$

In point (1) of the appendix the optimal production policy is derived:

$y_{i, 1}=\frac{1}{\varepsilon_{0}} \operatorname{Max}\left\{0, \varepsilon_{0}\right\} \bar{y} \quad$ with $\varepsilon_{0} \equiv \lambda_{0}-c_{0}$.

As a matter of convention, we define an expansion when $\varepsilon_{0} \geqslant 0^{7}$ and a recession when $\varepsilon_{0}<0$. The intuition is that in an expansion the entrepreneur outweighs the marginal production benefit $\left(\lambda_{0}\right)$ with the marginal production costs $\left(c_{0}\right)$, and vice versa in a recession. ${ }^{8}$

The optimal production policy is rather extreme. If $c_{0} \leqslant \lambda_{0}$, it is optimal for the firm to produce at full capacity $(\bar{y})$. If $c_{0}>\lambda_{0}$, the null production $y=0$ is the best alternative for the firm. ${ }^{9}$ When $n_{i, 0}$ is low, ${ }^{10}$ and the demand is high enough, then, some backlogs can be generated in a recession. These backlogs will be eliminated in future $\varepsilon_{0}$ positive periods, once firms produce $\bar{y}$ (as we have assumed $\left.\bar{y} \geqslant\left(\bar{a}-\lambda_{0}\right) /(1+b)-n_{0}\right)$. Finally, a positive correlation between $y_{1}$ and $\lambda_{0}$ is found, which is consistent with the sales reduction, as an inventory increasing strategy as $\lambda_{0}$ rises. This contrasts with Glazer's [7] result. There, LT debt induces a collusive agreement between oligopolistic firms, which restrain their production. This effect cannot be contemplated in our non-strategic model.

\footnotetext{
${ }^{6}$ The region $a_{1}<X_{1}$ is not considered because in this case the entrepreneur loses the firm's property rights.

${ }^{7}$ This definition of $\varepsilon_{0}$ makes its maximum amount equal to $\lambda_{0}$.

${ }^{8}$ We consider $\lambda_{0}$ independent of $c_{0}$. This is a consequence of assuming that $\tilde{c}$ follows an independent distribution over different periods. If we were allowed some correlation between $\tilde{a}$ and $\tilde{c}$, then, in periods of expansion, a reduction in $c_{0}$ would have to be accompanied by a rise in $\lambda_{0}$, this being the opposite in a period of recession.

${ }^{9}$ This corner solution is not maintained when we consider non-linear cost functions like $C=\frac{1}{2} c y^{2}$. In that case, $y_{1}$ would have been an interior solution

${ }^{10} \mathrm{In}$ fact it is only required that $n_{i, 0}<\left(\bar{a}-\lambda_{0}\right) /(1+b) \equiv \bar{n}_{0}$.
} 
Computing $\hat{n}_{1}-n_{0} \equiv \widehat{\Delta n}$, we obtain

$$
\begin{aligned}
\Delta \hat{n}=\frac{1}{(\bar{a}-\underline{a})}[ & -n_{i, 0}\left(X_{1}-\underline{a}\right) \\
& \left.+\int_{X_{1}}^{\bar{a}}\left\{\delta \bar{y}-\frac{a_{1}-\lambda_{0}}{1+b}\right\} \mathrm{d} a_{1}\right] .
\end{aligned}
$$

The term $-n_{i, 0}\left(X_{1}-\underline{a}\right) /(\bar{a}-\underline{a})$ accounts for the stock liquidation when the lender takes firm control and sells all the inventories. ${ }^{11}$

Proposition 1. Assuming $n_{0}$ high enough $\left(n_{0} \geqslant\right.$ $\left.n\left[X_{1}\right] \equiv\left(X_{1}-\lambda_{0}\right) /(1+b)\right),{ }^{12}$ and $\bar{y}$ high enough $\left(n_{0}+\bar{y} \geqslant \bar{n} \equiv\left(\bar{a}-\lambda_{0}\right) /(1+b)\right)$, we find that exclusively equity-financed firms $(B=0)$ store a higher inventory level than bank-debt financed firms. Concerning market structure, in a recessive (expansive) period, the more monopolistic (competitive) a market, the lower a firm's stock variation. Once the firm is financed with a proportion of bank debt as well as equity, the higher the firm's ST debt (B), the higher (lower) the firm's stock variation in recessions (expansions). Furthermore, a rise in market's $\lambda_{0}$ (inversely related with $S T$ debt), decreases (increases) stock variation in recessive (expansive) periods.

Proof. See point (2) in the appendix.

In the so-called recessive framework, the firm's null production makes inventory policy identical to sales policy. As sales are higher in competitive markets, it is reasonable to predict larger stock fluctuations under this market structure in recessions. Concerning the influence of a firm's debt liabilities on its inventory policy, the lower a firm's ST debt obligations, modeled by a low $B$ or a high proportion of long-length instruments with regard to ST debt (high $\lambda_{0}$ ), the higher a firm's stock investment. This leads to a reduced inventory variation in the null-production periods, and a higher stock variation in the full-capacity production periods. This

\footnotetext{
${ }^{11}$ This term is not present when there is an exclusive equity financing. In that case as $B=0$, we can ensure that $X_{1}=a$.

${ }^{12}$ This condition ensures that in a period of recession, the initial stock $n_{0}$ is high enough to satisfy the demand for the threshold level, $X_{1}$, to maintain the control of the firm by the entrepreneur.
}

dynamics of high inventory investment is exacerbated once firms have no debt liabilities (pure equity-financed firms).

\subsection{Market debt financing}

This financial scheme is symmetric to the previous one, with the only difference that firms cannot use inventories as a way of payment of their financial obligations. Thus, $\lambda^{\text {Market }}=0$. Moreover, we can consider that a market debt-financed firm's $\lambda$ is lower than a bank debt-financed firm's $\lambda$. Both facts make liquidity considerations very relevant in this financing scenario. Hendel [2] reports several examples of firms that have strongly reduced their inventories to fit their $S T$ financial obligations. This is an expression of what we call liquidity effect.

\subsubsection{Sales policy}

To characterize the optimal sales policy, we have to distinguish three cases:

(1) If first-period demand shocks are high enough, so that the firm's "liquid" profits (defined above) are higher than ST financial obligations $B$. In this case the sales policy is equivalent to that found under the bank-financing scenario ${ }^{13}$

$$
\begin{aligned}
& q_{i, 1}=\frac{a_{1}-\lambda_{0}}{1+b} \text { if } X_{1} \leqslant a_{1}, \\
& \left(X_{1}-\lambda_{0}\right)\left(X_{1}+b \lambda_{0}\right)-\left(1-b^{2}\right)\left(X_{1}-\lambda_{0}\right) \hat{Q} \\
& -\left(1+b^{2}\right)\left[c_{0} y_{i, 1}+A n_{i, 0}+B\right]=0 .
\end{aligned}
$$

(2) For medium-size first-period shocks $\left(Z_{1}<a_{1}<X_{1}\right){ }^{14}$ the entrepreneur wants to obtain the maximum amount of cash in order to keep

\footnotetext{
${ }^{13}$ Expression (8) is equivalent to the $X_{1}$ definition for the bank financing scenario (3), but without including the term $\lambda n_{i, 1}$ in the firm profit function, that is $V_{i, 1}\left[X_{1}\right]-\lambda n_{i, 1}=0$

${ }^{14}$ The $Z_{1}$ threshold value is obtained under the condition that "liquid" profits be higher than $B$, and making use of sales policy (9).
} 
his or her control of the firm. He or she maximizes the "liquid" profit function:

$$
\begin{aligned}
& q_{i, 1}=\frac{a_{1}}{1+b} \text { if } Z_{1} \leqslant a_{1}<X_{1} \\
& Z_{1}^{2}-\left(1-b^{2}\right) Z_{1} \hat{Q}-\left(1+b^{2}\right)\left[c_{0} y_{i, 1}+A n_{i, 0}+B\right] \\
& \quad=0 .
\end{aligned}
$$

(3) If $a_{1}<Z_{1}$, the lender takes over the firm's control and liquidates all the stocks

Two points are worth mentioning here. First, for medium-size first-period shocks $\left(Z_{1} \leqslant a_{1}<X_{1}\right)$, firms do not sell the optimal level $q=\left(a_{1}-\lambda_{0}\right) /(1+b)$, but a higher amount $q=a_{1} /(1+b)$, in order to prevent the lender from taking control of the firm. This is the expression of what we have defined as liquidity effect. Second, in competitive markets ( $b$ low) the low-price-big-sales policy generates an amount of cash high enough to make liquidity constraints non-binding. In that case, the liquidity effect is not shown. We can state that market effect outweights liquidity effect. This is clarified in the following lemma:

Lemma. When the lender requires liquid payments, $\left(\lambda^{\text {Market }}=0\right)$, the entrepreneur defines an aggressive sales policy for low demand shocks $\left(Z_{1} \leqslant a_{1}<X_{1}\right)$. This behavior is only present in fragmented-type markets, with $b>b^{*} \equiv 1-\lambda_{0} / X_{1}$. In more competitive markets, the market structure leads to a higher sales volume, thus making liquidity effects irrelevant.

Proof. See point (3) in the appendix.

\subsubsection{Production policy}

To compute a firm's optimal $y_{i, 1}$ amount, we distinguish two situations (according to the previous lemma):

3.2.2.1. $b \leqslant b^{*}$ (Quite-competitive markets): The maximization problem is formally identical to the bank-debt financing scenario. The only difference is in the threshold value $X_{1}$ which is given by expression (8). Making use of the sales policy (7), production $y_{i, 1}$ is given by

$$
\begin{aligned}
& y_{i, 1}=n_{i, 1}\left[X_{1}\right]=n_{i, 0}+\varepsilon_{0} \frac{X_{1}\left(\bar{a}-X_{1}\right)}{(1+b) \lambda_{0}\left(\lambda_{0}-\varepsilon_{0}\right)} \\
& \text { with } n_{i, 1}\left[X_{1}\right] \equiv \frac{X_{1}-\lambda_{0}}{1+b} .
\end{aligned}
$$

From the previous expression, and the assumption made throughout the paper of $n_{0}>n_{i, 1}\left[X_{1}\right]$, we obtain an $\varepsilon_{0}^{*}>0 .{ }^{15}$ For $\varepsilon_{0} \leqslant \varepsilon_{0}^{*}$, it is optimal to produce nothing, and, for $\varepsilon_{0}>\varepsilon_{0}^{*}$, we find an $\varepsilon_{0}$ increasing production function. The production function (11) is composed of two terms. The first term $n_{i, 1}\left[X_{1}\right]-n_{i, 0}$ is negative, and shows the remaining stocks once the entrepreneur has satisfied the threshold demand $\left(a_{1}=X_{1}\right)$ that secures his or her control over the firm. The second term, $\varepsilon_{0} X_{1}\left(\bar{a}-X_{1}\right) /(1+b) \lambda_{0}\left(\lambda_{0}-\varepsilon_{0}\right), \quad$ is a mixture of different magnitudes that stimulate the firm's production. The parameter $\varepsilon_{0}$ reflects economic environment conditions (expansions or recessions). The expression $X_{1}\left(\bar{a}-X_{1}\right) / \lambda_{0}$ balances the marginal revenues from selling stocks with the marginal benefits from accumulating stocks $\left(\lambda_{0}\right)$. Production cost considerations are present in $1 / c_{0} \equiv 1 /\left(\lambda_{0}-\varepsilon_{0}\right)$. Finally, $1 /(1+b)$ synthesizes market structure effects. In monopolistic environments $(b \rightarrow 1)$, the optimal level of sales (and production) is lower than in competitive markets.

Proposition 2. Market debt-financed firms have on average a lower stock level than bank debt-financed firms whenever $n_{0}>n\left[X_{1}\right]$, and $\bar{y}$ is high enough $\left(n_{0}+\bar{y} \geqslant \bar{n} \equiv\left(\bar{a}-\lambda_{0}\right) /(1+b)\right)$. For high values of debt and low values of $\lambda_{0},{ }^{16}$ we find that $\hat{n}_{1}$ and $B$ are negatively correlated, as well as stock variation $\left|\hat{n}_{1}-n_{0}\right|$ and $\lambda_{0}$. This last correlation only works for low and high $\varepsilon_{0}$ values and when $n_{0}<\bar{n}$ (non-trivial

\footnotetext{
${ }^{15}$ It is straightforward to compute

$\varepsilon_{0}^{*}=\lambda_{0}\left[1-\frac{1}{1-\left[\lambda_{0}(1+b) / X_{1}\left(a-X_{1}\right)\right]\left(n\left[X_{1}\right]-n_{0}\right)}\right]$,

where the value of $X_{1}$ is given by expression (8). Note that our assumption of $n_{i, 0} \geqslant n\left[\underline{X}_{1}\right] \Rightarrow \varepsilon_{0}^{*} \geqslant 0$.

${ }^{16}$ In fact both conditions are related, as the higher is ST debt (high $B$ ), the lower is the proportion of LT debt to ST debt (low $\lambda_{0}$ ). In point 3 in the appendix is shown $B$ and $\lambda_{0}$ must ensure $\partial y_{1} / \partial X_{1}=[1 /(1+b)]\left(1+\varepsilon_{0} \bar{a}-2 X_{1} / \lambda_{0}\left(\lambda_{0}-\varepsilon_{0}\right)\right)<0$.

This can be accomplished if $B$ is high and $\lambda_{0}$ is low.
} 
case). Both facts suggest the following policy measure that a Central Authority may adopt in order to smooth business cycle fluctuations: Reducing the official rates during recessions so that firms could renegotiate their ST debt. This becomes LT debt, payable in future expansions. This policy will reduce $B$ and raise $\lambda_{0}$ in a recessive period, and increase $B$ in eventual future expansive periods.

Proof. See point (4) in the appendix.

When we compare stock fluctuations under both financing scenarios, we see that in recessions, market debt-financed firms tend to adjust more their stocks as they store a lower level of inventories. In expansions, firms tend to adjust their stocks less, as they invest in inventories less strongly than bank debt-financed firms.

Regarding the relationship between firms' financial structure and firms' inventory policy, the results are qualitatively identical to the previous scenario. The only difference is that for high values of $\varepsilon_{0}$, there is a negative correlation between $\hat{n}_{1}$ and $\lambda_{0}$. This implies that the reduction of firms' stock investments has to be achieved through increases in $\lambda_{0}$. To see this, note that a rise in $\lambda_{0}$ leads to a reduction in firm sales and therefore in current revenues, which are in turn invested in valuable inventories to be cashed in the future. The point is that these stocks are perfect substitutes of cash only under bank financing, but not under market financing, as they cannot be used as a means of payment. We obtain in this way a clear disincentive to reduce sales to accumulate stocks in the market financing scenario as $\lambda_{0}$ rises. In this case - unlike in the bank financing scenario - a rise in $\lambda_{0}$ is associated with an increase in the threshold level $X_{1}$.

Finally, an alternative measure that a Central Authority can adopt is to promote the use of variable-rate credits. This would also lead a profitmaximizing firm to smooth its inventory policy. In recession, rates generally decrease to stimulate the economy. In expansions, the Central Bank increases interest rates to smooth inflationary pressure. Within this setting, interest payments will be lower in recessions (reduction in B), and higher in expansions (raising firms' liquidity needs, which give firms disincentives to invest strongly in stocks).
3.2.2.2. $b>b^{*}$ : In this case, the maximization problem faced by the entrepreneur becomes

$$
\begin{aligned}
\underset{\left\{y_{i, 1}\right\}}{\operatorname{Max}} & V_{i, 0} \\
V_{i, 0} \equiv & \int_{Z_{1}}^{X_{1}}\left\{\underline{R}_{i, 1}-c y_{i, 1}-A n_{i, 0}-B\right\} \frac{\mathrm{d} a_{1}}{\Delta a} \\
& +\int_{X_{1}}^{\bar{a}}\left\{\bar{R}_{i, 1}-c y_{i, 1}-A n_{i, 0}+\lambda_{0} n_{i, 1}-B\right\} \frac{\mathrm{d} a_{1}}{\Delta a},
\end{aligned}
$$

where $Z_{1}, X_{1}$ are given by (10) and (8), $R_{i, 1}=$ $\left(a_{1}-b a_{1} /(1+b)-(1-b) \hat{Q}\right)\left(a_{1} /(1+b)\right)$ and $\bar{R}_{i, 1}=$ $\left(a_{1}-b\left(a_{1}-\lambda_{0}\right) /(1+b)-(1-b) \hat{Q}\right)\left(\left(a_{1}-\lambda_{0}\right) /\right.$ $(1+b))$.

The value function in the interval $Z_{1} \leqslant a_{1}<X_{1}$ does not include the term $\lambda_{0} n_{i, 1}$, because this is the region where the liquidity effect is present. Moreover, in this region, the sales policy becomes $q_{i, 1}=a_{1} /(1+b)$.

By computing the FOC of the problem in (12), we characterize the optimal production policy $y_{i, 1}$ as a function of the threshold values $Z_{1}$ and $X_{1}$ :

$$
\begin{aligned}
y_{i, 1}= & n_{i, 1}\left[X_{1}\right]-n_{i, 0}+\varepsilon_{0} \frac{X_{1}\left(\bar{a}-X_{1}\right)}{(1+b) \lambda_{0}\left(\lambda_{0}-\varepsilon_{0}\right)} \\
& -\frac{X_{1}-Z_{1}}{\lambda_{0}(1+b)^{2}}\left[X_{1}-b Z_{1}\right] .
\end{aligned}
$$

By comparing expressions (13) and (11) we can see that production in the less competitive scenario $\left(b>b^{*}\right)$ is lower than that obtained in the competitive framework. This is due to the presence of two factors: first, the market structure, which makes firms more aggressive in a competitive environment; and second, the higher threshold-value, $\varepsilon_{0}^{*}$ (below which the supply shocks lead to a null production). The analysis of the inventory policy in this region does not provide new insights with respect to the previous $b$-region.

\section{Discussion and conclusions}

We have studied firm inventory policy in an environment with supply and demand shocks, 
taking into consideration different product market structures as well as firm financial structures. We have shown that in an expansive (recessive) period, inventory variance increases (decreases) as markets become more fragmented.

Concerning firm financial structure, we have found that market debt-financed firms store a lower level of inventories than bank debt-financed firms, which in turn accumulate less than equity-financed firms. This particular ranking can be explained in terms of liquidity considerations. Equity-financed firms do not have liquidity obligations to be satisfied and, during expansions, can invest freely in illiquid assets such as stocks. This is not the case for debt-financed firms, especially if debt is short term. These firms need to keep a substantial amount of resources in cash, in order to satisfy their monetary obligations and avoid liquidation. This fact discourages them from implementing an aggressive policy of stock accumulation during expansions and, by the same token, leads to a strong inventory disinvestment in recessions. Such liquidity effect is particularly important for market debt-financed firms, as they cannot use inventories as a means of payment. As a consequence, the higher (lower) the amount of ST debt in expansions (recessions), the lower stock fluctuations in expansions (recessions) for a profit-maximizing firm. This in turn implies that firms using ST variable-rate credit (more cash demanding in expansions than in recessions) will define a smoother inventory policy than those using fixed-rate credit.

On the basis of the previous analysis, we could describe a mechanism that stimulates profit-maximizing firms to smooth their inventory policy while obtaining "cheap" financing. This consists of raising funds in a recessive period, making use of LT convertible debt. These bonds would incorporate two ex-ante conditions: first, they must be transformed in equity in the next expansive period, and second, there must be a firm commitment to buy back a certain proportion of this equity. The buyback commitment will make this instrument attractive to potential lenders, providing firms "cheap" liquidity in recessive periods and avoiding an inventory overselling. At the same time, the use of available resources in expansions for the purchase of equities committed ex-ante will prevent a substantial investment in non liquid assets such as inventories.

As a final remark, an interesting extension to this model would contemplate issues of aggregation of firms' inventory policies across markets subject to idiosyncratic shocks. This would provide an insightful alternative to the case of common shocks analyzed in this paper. Such an extension is left for future research.

\section{Appendix}

(1) Derivation of the optimal production policy

$$
\begin{aligned}
\frac{\partial V_{i, 0}}{\partial y_{i, 1}}= & \int_{X_{1}}^{\bar{a}}\left\{-c_{0}+\lambda_{0}\right\} \frac{\mathrm{d} a_{1}}{\Delta a} \\
& -\frac{\partial X_{1}}{\partial y_{i, 1}} \int_{X_{1}}^{\bar{a}}\left\{R_{i, 1}\left[X_{1}\right]-c_{0} y_{i, 1}-A n_{i, 0}\right. \\
& \left.+\lambda_{0} n_{i, 1}\left[X_{1}\right]-B\right\} \frac{\mathrm{d} a_{1}}{\Delta a} \\
= & \varepsilon_{0}\left(\frac{\bar{a}-X_{1}}{\bar{a}-a}\right)-\frac{\partial X_{1}}{\partial y_{i, 1}}\left(\frac{\bar{a}-X_{1}}{\bar{a}-a}\right) V_{i, 0}\left[X_{1}\right] \\
= & \varepsilon_{0}\left(\frac{\bar{a}-X_{1}}{\bar{a}-a}\right)
\end{aligned}
$$

because $V_{i, 0}\left[X_{1}\right]=0$ by the definition of $X_{1}$. Thus, we can ensure that $\partial V_{i, 0} / \partial y_{i, 1} \lessgtr 0$ for $\varepsilon_{0} \gtrless 0 \Rightarrow y_{i, 1}=0 / y$ for $\varepsilon_{0} \gtrless 0$, where $\bar{y}$ is firm's capacity. Therefore $y_{i, 1}=\left(1 / \varepsilon_{0}\right) \max \left\{0, \varepsilon_{0}\right\} \bar{y}$

\section{(2) Proof of Proposition 1}

To determine the relationship between $\hat{n}_{1}, b, B$ and $\lambda_{0}$, we first compute $\hat{n}_{1}$ :

$$
\begin{gathered}
\hat{n}_{1}=\frac{\left(\bar{a}-X_{1}\right)}{\bar{a}-\underline{a}}\left\{n_{0}+\delta \bar{y}-n^{+}\left[X_{1}\right]\right\} \\
\text { with } n^{+}\left[X_{1}\right]=\frac{1}{2} \frac{\left(\bar{a}+X_{1}\right)-\lambda_{0}}{1+b} .
\end{gathered}
$$

$\delta=1(0)$, depending if there is an expansive (recessive) period.

(2.1) Concerning the relationship between $\hat{n}_{1}$ and $B$ we have $\mathrm{d} \hat{n}_{1} / \mathrm{d} B=\left(\partial \hat{n}_{1} / \partial X_{1}\right) \partial X_{1} / \partial B$. To compute $\partial X_{1} / \partial B$, we use expression (3), taking $\hat{Q}$ as a constant, as we consider changes in $B$ for particular firm, taking other firms' $B$ as 
constants. The result is $\partial X_{1} / \partial B=(1+b) /$ $\left(X_{1}-\lambda_{0}\right)>0$, as $n\left[X_{1}\right]=\left(X_{1}-\lambda_{0}\right) /(1+b)>0$. We compute $\partial \hat{n}_{1} / \partial X_{1}$ from (A.1) to obtain

$$
\begin{aligned}
& \frac{\partial \hat{n}_{1}}{\partial X_{1}}=\frac{1}{(\bar{a}-\underline{a})}\left\{n\left[X_{1}\right]-n_{0}-\delta \bar{y}\right\}<0 \\
& \quad \text { as } n\left[X_{1}\right]<n_{0} .
\end{aligned}
$$

From (A.2), and $\partial X_{1} / \partial B>0$, we can ensure $\mathrm{d} \hat{n}_{1} / \mathrm{d} B<0 \Rightarrow$ lower $\hat{n}_{1}$ in equity-financed firms $(B=0)$; and $\mathrm{d} \mid \Delta \hat{n} / \mathrm{d} B>(<) 0$ in recessive (expansive) periods, as $\Delta \hat{n} \equiv \hat{n}_{1}-n_{0}$ is negative (positive) in the former (latter) periods.

(2.2) To relate $\hat{n}_{1}$ with $b$, we compute $\mathrm{d} \hat{n}_{1} / \mathrm{d} b=$ $\left(\partial \hat{n}_{1} / \partial X_{1}\right) \partial X_{1} / \partial b+\left(\partial \hat{n}_{1} / \partial b\right) \partial X_{1} / \partial b$, is obtained under expression (3), assuming a symmetric solution $\hat{Q}=q_{i}$. In contrast to the previous point, we cannot take $\hat{Q}$ as a constant because $b$ affects the sales policy of all firms. In this case expression (3) becomes

$$
\begin{aligned}
& b\left(X_{1}-\lambda_{0}\right)^{2}-(1+b)^{2}\left[-\varepsilon_{0} y_{i, 1}\right. \\
& \left.+\left(A-\lambda_{0}\right) n_{i, 0}+B\right]=0 .
\end{aligned}
$$

Therefore, making use of (A.3), we get $\partial X_{1} / \partial b=-(1-b)\left(X_{1}-\lambda_{0}\right) / 2 b(1+b)$, which leads to

$$
\begin{aligned}
\frac{\mathrm{d} \hat{n}_{1}}{\mathrm{~d} b}= & \frac{1}{(\bar{a}-a)}\left\{( \frac { ( 1 - b ) } { 2 b } ) n [ X _ { 1 } ] \left(n_{0}+\delta y\right.\right. \\
& \left.\left.-n\left[X_{1}\right]\right)+\frac{\left(\bar{a}-X_{1}\right)}{1+b} n^{+}\left[X_{1}\right]\right\} .
\end{aligned}
$$

Assumption $n_{0}>n\left[X_{1}\right] \forall X_{1}$ allows us to prove $\mathrm{d} \hat{n}_{1} / \mathrm{d} b>0 \Rightarrow \mathrm{d} \mid \Delta \hat{n} / \mathrm{d} b<(>) 0$ in recessive (expansive) periods.

(2.3) Finally, to determine the relationship between $\hat{n}_{1}$ and $\lambda_{0}$, we use $\mathrm{d} \hat{n}_{1} / \mathrm{d} \lambda_{0}=$ $\left(\partial \hat{n}_{1} / \partial X_{1}\right) \partial X_{1} / \partial \lambda_{0}+\partial \hat{n}_{1} / \partial \lambda_{0}$ where $\partial \hat{n}_{1} / \partial X_{1}$ is given by (A.2). From (A.1) we compute $\partial \hat{n}_{1} / \partial \lambda_{0}=\left(\bar{a}-X_{1}\right) /(\bar{a}-\underline{a})(1+b)$. Reasoning as we did in the comparative static analysis over $B$, we use (3) to get $\partial X_{1} / \partial \lambda_{0}=$ $1-n_{0} / n\left[X_{1}\right]$. Joining them together, we get

$$
\begin{aligned}
\frac{\mathrm{d} \hat{n}_{1}}{\mathrm{~d} \lambda_{0}}= & \frac{1}{(\bar{a}-\underline{a})}\left[\left(n\left[X_{1}\right]-n_{0}-\delta \bar{y}\right)\left(1-\frac{n_{0}}{n\left[X_{1}\right]}\right)\right. \\
& \left.+\frac{\left(\bar{a}-X_{1}\right)}{(1+b)}\right] .
\end{aligned}
$$

Assumption $n_{0}>n\left[X_{1}\right] \Rightarrow \mathrm{d} \hat{n}_{1} / \mathrm{d} \lambda_{0}>0 \Rightarrow$ $\mathrm{d} \mid \Delta \hat{n} / \mathrm{d} \lambda_{0}<(>) 0$ in recessions (expansions).

\section{(3) Proof of the Lemma}

To prove the lemma, we use expressions (8) and (10), considering the symmetric solution $q_{i}=\hat{Q}=\left(X_{1}-\lambda_{0}\right) /(1+b) \quad$ for $\quad$ (8) and $q_{i}=\hat{Q}=Z_{1} /(1+b)$ for $(10)$. The result is

$$
\begin{gathered}
A\left[X_{1}\right] \equiv X_{1}^{2} b-(1+b)^{2}\left[c_{0} y_{i, 1}+A n_{i, 0}+B\right] \\
+\lambda_{0} X_{1}\left[b^{*}-b\right]=0, \\
\left.B\left[Z_{1}\right] \equiv Z_{1}^{2} b-(1+b)^{2}\left[c_{0} y_{i, 1}+A n_{i, 0}+B\right]=0.5\right)
\end{gathered}
$$

As $A\left[X_{1}\right]$ and $B\left[Z_{1}\right]$ are increasing in $X_{1}$, and $Z_{1}$, respectively, we can ensure that for $b \gtrless b^{*} \Rightarrow X_{1} \gtrless Z_{1}$.

\section{(4) Proof of Proposition 2}

(1) To prove that the inventory level in market debt-financed firms is lower than in bank debtfinanced firms we look at expressions (A.3) and (A.5), which define $X_{1}^{M}$ and $X_{1}^{B}$. (upper index $M(B)$ for market (bank) financing scenario):

$$
\begin{aligned}
P_{1}\left[X_{1}^{B}\right] \equiv & \frac{b\left(X_{1}^{B}-\lambda_{0}\right)^{2}}{(1+b)^{2}} \\
& +n_{0}\left(\lambda_{0}-A\right)-\left(-\varepsilon_{0} y^{B}+B\right)=0,
\end{aligned}
$$

$$
\begin{aligned}
P_{2}\left[X_{1}^{M}\right] \equiv & \frac{b\left(X_{1}^{M}-\lambda_{0}\right)^{2}}{(1+b)^{2}}+n_{0}\left(\lambda_{0} \frac{n\left[X_{1}^{M}\right]}{n_{0}}-A\right) \\
& -\left(c_{0} y^{M}+B\right)=0 .
\end{aligned}
$$

As $y^{B} \geqslant y^{M}$ (see (5) and (11)), $\varepsilon_{0}>-c_{0}$ and $n_{0}>n\left[X_{1}\right]$, we can ensure

$$
P_{1}\left[X_{1}\right]>P_{2}\left[X_{1}\right] \Rightarrow X_{1}^{B}<X_{1}^{M}\left(\frac{\partial P\left[X_{1}\right]}{\partial X_{1}}>0\right) .
$$

Eq. (11) allows us to define $\bar{\varepsilon}_{0}$, as the value of $\varepsilon_{0}$ such that $y^{M}=\bar{y}$. Thus, for $\varepsilon_{0} \leqslant 0\left(>\bar{\varepsilon}_{0}\right)$ $\Rightarrow y^{B}=y^{M}=0(\bar{y})$, and we can apply (A.2) to (A.8) to obtain $\hat{n}_{1}^{M}<\hat{n}_{1}^{B}$. 
For $0<\varepsilon_{0}<\bar{\varepsilon}_{0}$, as $y^{B}=\bar{y}>y^{M}$, a continuity argument ensures

$$
\begin{aligned}
\hat{n}_{1}^{B} & =\frac{\left(\bar{a}-X_{1}^{B}\right)}{\bar{a}-\underline{a}}\left\{n_{0}+\bar{y}-n^{+}\left[X_{1}^{B}\right]\right\}>\hat{n}_{1}^{M} \\
& =\frac{\left(\bar{a}-X_{1}^{M}\right)}{\bar{a}-\underline{a}}\left\{n_{0}+y^{M}-n^{+}\left[X_{1}^{M}\right]\right\} .
\end{aligned}
$$

(2) The second issue to study is the relationship between $\hat{n}_{1}^{M}$ and $B$.

To compute $d \hat{n}_{1}^{M} / d B=\partial \hat{n}_{1}^{M} / \partial X_{1} \partial X_{1} / \partial B$, we distinguish three $\varepsilon_{0}$-regions (we drop upper in$\operatorname{dex} M$ when not necessary):

(a) For $\varepsilon_{0} \leqslant \varepsilon_{0}^{*}$ and $\varepsilon_{0} \geqslant \bar{\varepsilon}_{0}$, expression (A.2) applies and $\partial \hat{n}_{1}^{M} / \partial X_{1}<0$. Moreover, expression (8) leads to $\partial X_{1} / \partial B=1 / X_{1}(1+b)>0$, therefore $\mathrm{d} \hat{n}_{1}^{M} / \mathrm{d} B<0$.

(b) For $\varepsilon_{0}^{*}<\varepsilon_{0}<\bar{\varepsilon}_{0}$, combining expressions (8) and (11) we obtain the expression that defines $X_{1}$. Once we apply the implicit theorem to this expression, we obtain $\partial X_{1} / \partial B=(1+b) /$ $\left(X_{1}-\left(1+\varepsilon_{0}\left(\bar{a}-2 X_{1}\right) / \lambda_{0}\left(\lambda_{0}-\varepsilon_{0}\right)\right)\right)>0$ as we have assumed in the proposition that $B$ and $\lambda_{0}$ are such that ensure

$\frac{\partial y_{1}}{\partial X_{1}}=\frac{1}{1+b}\left(1+\varepsilon_{0} \frac{\bar{a}-2 X_{1}}{\lambda_{0}\left(\lambda_{0}-\varepsilon_{0}\right)}\right)<0$.

On the other hand, combining (11) and $\hat{n}_{1}=\left[\left(\bar{a}-X_{1}\right) /(\bar{a}-\underline{a})\right]\left\{n_{0}+y-n^{+}\left[X_{1}\right]\right\}$, we obtain

$$
\begin{aligned}
\hat{n}_{1}^{M}= & \frac{\left(\bar{a}-X_{1}\right)}{\bar{a}-\underline{a}}\left\{n\left[X_{1}\right]-n^{+}\left[X_{1}\right]\right. \\
& \left.+\varepsilon_{0} \frac{X_{1}\left(\bar{a}-X_{1}\right)}{(1+b) \lambda_{0}\left(\lambda_{0}-\varepsilon_{0}\right)}\right\} .
\end{aligned}
$$

Deriving this expression we get

$\frac{\partial \hat{n}_{1}^{M}}{\partial X_{1}}=\frac{\bar{a}-X_{1}}{(\bar{a}-\underline{a})(1+b)}\left\{1+\varepsilon_{0} \frac{\bar{a}-3 X_{1}}{\lambda_{0}\left(\lambda_{0}-\varepsilon_{0}\right)}\right\}$.

Eq. (A.11) is negative by (A.9), which combined with $\partial X_{1} / \partial B>0$ leads to $\mathrm{d} \hat{n}_{1}^{M} / \mathrm{d} B<0$.

(3) The last issue is to study the correlation between $\hat{n}_{1}^{M}$ and $\lambda_{0}$.

To compute $\mathrm{d} \hat{n}_{1}^{M} / \mathrm{d} \lambda_{0}=\left(\partial \hat{n}_{1}^{M} / \partial X_{1}\right) \partial X_{1} / \partial \lambda_{0}+$ $\partial \hat{n}_{1}^{M} / \partial \lambda_{0}$, we use the same partition as before: (a) For $\varepsilon_{0} \leqslant \varepsilon_{0}^{*}$ and $\varepsilon_{0} \geqslant \bar{\varepsilon}_{0}$, we apply expression (A.1) to obtain $\partial \hat{n}_{1}^{M} / \partial \lambda_{0}=\left(\bar{a}-X_{1}\right) /$ $(\bar{a}-a)(1+b) . \quad$ Expression (8) leads to $\partial X_{1} / \partial \lambda_{0}=\lambda_{0} / X_{1}>0$, and $\partial \hat{n}_{1}^{M} / \partial X_{1}$ is given by (A.2), thus,

$$
\begin{aligned}
& \frac{\mathrm{d} \hat{n}_{1}^{M}}{\mathrm{~d} \lambda_{0}}=\frac{1}{(\bar{a}-\underline{a})}\left\{\left(n\left[X_{1}\right]-n_{0}-\delta \bar{y}\right) \frac{\lambda_{0}}{X_{1}}\right. \\
& \left.+\frac{\left(\bar{a}-X_{1}\right)}{(1+b)}\right\} \text {. }
\end{aligned}
$$

As $\lambda_{0} / X_{1}<1$ and $n\left[X_{1}\right]<n_{0}<\left(\bar{a}-\lambda_{0}\right) /$ $(1+b) \Rightarrow$ For $\delta=0, \quad \mathrm{~d} \hat{n}_{1}^{M} / \mathrm{d} \lambda_{0}>[1 /(\bar{a}-a)]$ $\left(\left(\bar{a}-\lambda_{0}\right) /(1+b)-n_{0}\right)>0$.

On the other hand if $\delta=1$ and $n_{0}+\bar{y}-\left(\bar{a}-X_{1}\right) /(1+b)>0, \quad$ then $\quad \mathrm{d} \hat{n}_{1}^{M} /$ $\mathrm{d} \lambda_{0}<0$.

For $\varepsilon_{0}^{*}<\varepsilon_{0}<\bar{\varepsilon}_{0}$, the expression $X_{1}$ is given combining (8) and (11), to compute

$$
\frac{\partial X_{1}}{\partial \lambda_{0}}=\frac{\lambda_{0}-1+X_{1}\left(\bar{a}-X_{1}\right) / \lambda_{0}^{2}}{X_{1}-\left(1+\varepsilon_{0}\left(\bar{a}-2 X_{1}\right) / \lambda_{0}\left(\lambda_{0}-\varepsilon_{0}\right)\right)}>0
$$

by (A.9). To compute $\partial \hat{n}_{1}^{M} / \partial \lambda_{0}$, we use (A.4), obtaining $\partial \hat{n}_{1}^{M} / \partial \lambda_{0}=X_{1}\left(\bar{a}-X_{1}\right)^{2} /(\bar{a}-a)(1+b)$ $\lambda_{0}^{2}>0$. Finally $\partial \hat{n}_{1}^{M} / \partial X_{1}$ is given by (A.11) which is negative, and very negative as $\varepsilon_{0}$ tends to $\bar{\varepsilon}_{0}$. Combining the three elements we can ensure the existence of an $\tilde{\varepsilon}_{0}$, such that $\varepsilon_{0}^{*} \leqslant \tilde{\varepsilon}_{0} \leqslant \bar{\varepsilon}_{0}$, where $\mathrm{d} \hat{n}_{1}^{M} / \mathrm{d} \lambda_{0}=\left(\partial \hat{n}_{1}^{M} / \partial X_{1}\right) \partial X_{1} /$ $\partial \lambda_{0}+\partial \hat{n}_{1}^{M} / \partial \lambda_{0} \gtrless 0$ for $\varepsilon_{0} \gtrless \tilde{\varepsilon}_{0}$. Therefore $\mathrm{d}\left|\hat{n}_{1}^{M}-n_{0}\right| / \mathrm{d} \lambda_{0}<0$ for $\varepsilon_{0}<0$ and $\varepsilon_{0}>\tilde{\varepsilon}_{0}$

\section{Acknowledgements}

I gratefully acknowledge the comments of Barbara Pettrongolo as well as those of the participants in the IX ASSET Congress (Marseille, 1997), in the 10th ISIR congress (Budapest, 1998), and the XXIII Simposio de Análisis Económico (Barcelona, 1998).

\section{References}

[1] A.S. Blinder, L.J. Maccini, Taking stock: A critical assessment of recent research on inventories, Journal of Economic Perspectives 5 (1) (1991) 73-96. 
[2] I. Hendel, Competition under financial distress, Journal of Industrial Economics 44 (1996) 309-324.

[3] R.E. Carpenter, S.M. Fazzari, B.C. Petersen, Inventory investment internal-finance fluctuations and business cycle, Brooking Papers on Economic Activity 2 (1994) 75-135.

[4] A.K. Kashyap, O.A. Lamont, J.C. Stein, Credit conditions and the cyclical behavior of inventories, Quarterly Journal of Economics 109 (3) (1994) 565-591.
[5] M. Olney, Credit as a production-smoothing device: The case of automobiles, 1913-38, Journal of Economic History 49 (2) (1989) 377-391.

[6] O. Hart, Firms, contracts and Financial Structure, Clarendon Press, Oxford, 1995.

[7] J. Glazer, The strategic effect of long-term debt in imperfect competition, Journal of Economic Theory 62 (1994) 428-443. 